\title{
International Contexts of Social Media and e-WoM Communication in the Customer Decision-Making Process ${ }^{1}$
}

\author{
Małgorzata Bartosik-Purgat ${ }^{2}$
}

Submitted: 02.05.17. Final acceptance: 05.02.18

\section{Abstract}

Purpose: The main purpose of the paper is to identify the importance of social media in e-WoM (electronic word of mouth) in relation to the two stages of consumer behavior, pre-purchase and post-consumption, in groups of different gender and countries. The article answers three research questions. Whether the frequency of using the most popular social media influences the range of using them in e-WoM among individual users? Which stage of consumer behavior process is more dependent on social media, pre-purchase or post-consumption? Do any differences exist between men and women in the scope under consideration?

Methodology: The analysis bases on literature studies and empirical data collected among 1246 respondents from four countries: China, Poland, the United States of America, and Turkey.

Findings: General conclusions show differences between these countries in relation to the use of social media for e-WoM. Moreover, results confirmed the findings of literature analysis wherever consumers used social media at the stage of looking for information and advice about products (pre-purchase). Gender appeared as a significant differentiating factor that influences e-WoM behavior.

Research limitations: The design of the research (samples' size and sampling method) could place some limits on the capacity of the study to generalize the results to other national contexts.

Research implications: The results offer information for marketers who use social media communication to build brands' loyalty in the international marketplace and individuals who rely on experiences shared through social media.

Originality: The content of the paper is important, timely, original, and focusses on the subject infrequently studied in the literature. The information from the paper applies to numerous groups of stakeholders.

Keywords: social media, e-Wom, communication, gender, consumer behavior process

JEL: M31, N30

\footnotetext{
The paper was prepared as part of scientific grant no. 2015/17/B/HS4/00309 of National Science Centre, Poland.

2 Poznań University of Economics and Business

Correspondence address: Poznań University of Economics and Business, Al. Niepodległości 10, 61-875 Poznań, Poland, e-mail: Malgorzata. Bartosik-Purgat@ue.poznan.pl
} 


\section{Introduction}

Combined with the needs of socio-cultural changes, innovation constantly develops new technologies. Every day, new technologies and the growth in the use of the Internet change people's lives throughout the world. The opportunities provided by the Internet continue to influence many areas of individual and business activities while, thanks to the development of new technologies, many changed their activities and the quality of their output (Ghezzi and Dramitinos, 2016). The Internet also allows users to freely communicate, gather information, and express opinions about others, companies, brands, and products.

Moreover, a significant breakthrough in the use of the Internet came with the emergence of social media (Barreto, 2014), which allows users to engage and function online in ways previously unavailable. Through social media, people not only maintain contact with friends but also gather facts about world events and exchange information about brands and companies. Social media have contributed to the development of how we convey information about products (Chu and Kim, 2011). In marketing literature, the way of exchanging such information among buyers in direct communication is called Word of Mouth (WoM); (Chu and Kim, 2011; Lin et al., 2014). Using the Internet for this purpose, including social media, has influenced the emergence of a new type of WoM, called e-WoM (Huang et al., 2011; Cheung and Thadani, 2012; Lin et al., 2014; Barreto, 2014). WoM and e-WoM are now extremely important sources of gathering information about products and brands before buying because they are much more trusted than other forms like advertising messages or recommendation of sellers or producers (Chu and Choi, 2011; Baird and Parasnis, 2011; Kucukemiroglu and Kara, 2015). Consumers ask other consumers via social media - like Facebook, YouTube, Qzone, or RenRen - what their opinions are about specific goods (Erkan and Evans, 2016). Such behavior usually appears before the decision to buy or after consumption - especially when the product is of bad quality - when consumers want to warn others of the low quality of products (See-To and Ho, 2014; Wang et al., 2016).

In many countries, the medium with the greatest number of active users and dominant player in the social media market is Facebook (Kemp, 2016). Facebook is a significant tool in the development and application of e-WoM, with many users who seek information from their 'friends' before making a decision about buying a particular product, (Ho, 2014; Kucukemiroglu and Kara, 2015; Davies et al., 2016). Negative opinions on Facebook about a brand can almost instantaneously potentially reach thousands (Bachleda and Berrada-Fathi, 2016), which can significantly influence decreasing reputation and credibility of a given product among prospective buyers (Ho, 2014). 
However, one should remember that national markets differ from one another in terms of popularity and the use of social media. Facebook is not universally popular, or available (Kemp, 2016). This is particularly the case in Asian and Russian markets where, instead of Facebook and Twitter, more popular remain the local media like Qzone, Weibo, WeChat, RenRen, or VKontakte (Kemp, 2015, 2016). In some Chinese provinces, Facebook is blocked (Blocked in China..., 2017), which is why the number of its users is lower than in other countries. This was the reason why Qzone - the Chinese equivalent of Facebook - entered this study.

Social media usage, its manner and platform, depends on many factors, among which sex is one of the most important. Women and men have different motivations and focus on satisfying different needs. For example, women often more center on the variety of details in products while men look more holistically (Trauth, 2013). In sociological literature, researchers identify different behaviors between men and women particularly about the method of communication and relationship management. Namely, scholars argue that women focus more on relationships while men on tasks (Deaux and Major, 1987); women are more likely than men to show preferences in relation to the maintenance of family ties (Di Leonardo, 1987), ties with friends, and involvement in social activities (Chan et al., 2015). This sociological background influences social media usage with regard to e-WoM activities.

The main purpose of the paper is to identify the importance of social media in e-WoM in relation to the two stages of consumer behavior - pre-purchase and post-consumption - with special attention to gender. The article answers three research questions. Whether the frequency of using the most popular social media influences the range of using them in e-WoM among individual users? Which stage of consumer behavior process is more dependent on social media, pre-purchase or post-consumption? Do any differences exist between men and women in the scope under consideration? The analysis bases on literature studies and empirical data collected among 1246 respondents from four countries: China, Poland, the United States of America, and Turkey. In the exploratory empirical study, the author used two research methods: PAPI (Paper and Pen Personal Interview) and CAWI (Computer Assisted Web Interview). The rationale for the choice of these countries is the different levels of their economic development and their exemplification of more generally 'Western' and 'Eastern' countries, which supports the further aim of the study to investigate whether e-WoM activities are universal or differ between regions. The results are important and can be useful for enterprises which plan activities in these particular countries and use social media in their marketing communication strategies. 
The first part of the paper includes an overview of the literature on consumer behavior, social media, e-WoM, and gender. Then, the author presents the research method and the results of the empirical study only to end with conclusions, implications, study limitations, and suggestions for future research.

\section{Literature Overview}

\section{Consumer Behavior Process: Theoretical Background}

Consumer behavior is a process that consists of activities aimed at meeting a particular need (Schiffman et al., 2010; Solomon et al., 2010; Galalae and Voicu, 2013). Hansen (1972) defines consumer behavior as a totality of actions and perceptions of an individual, which comprise preparations for the decision to buy a product, its choice, and consumption. In this case, consumer behavior relates to three types of reaction: communication, purchase, and consumption (Hansen, 1972, p. 17). In this paper, we call these stages pre-consumption, consumption, and post-consumption. In the literature, there is a number of traditional consumer behavior models (e.g. Andreasen, Howard-Sheth or Engel-Blackwell-Kollat model). One of the basic characteristics in the most popular behavior model is the quantity and variety of factors that influence the stages of communication and purchase (Andreasen, 1965; Engel et al., 1968; Howard and Sheth, 1969). One of the main determinants is information about the product that a consumer wants to buy. There are many different sources of pre-consumption information. Today, the Internet is usually the first and most dominant source of information about brands that people think of buying. That is why the e-WoM concept develops so fast and plays an important role in the process of consumer decision. The first stage of consumer behavior is to search for information about the product (pre-consumption stage), while the final post-consumption stage refers to post-use/post-consumption experiences (Blackwell et al., 2001, p. 159-175).

\section{Electronic Word of Mouth}

Marketing theory calls a direct form of exchanging marketing information about a product - its collecting and conveying - Word-of-Mouth (WoM); because it takes place face to face. It is an informal method of communication (Chu and Kim, 2011) and a channel of interpersonal communication, whose actors are neighbors, friends, or family that express opinions in interactions with potential and current buyers of products (Lin et al., 2014). WoM is a result of customer satisfaction: the higher the satisfaction, the more positive an opinion about a product, brand, and the whole enterprise will be (Jalilvand and Samiei, 2012). Positive opinions among customers contribute to the 
construction of a good brand and company image (Chu and Kim, 2011; Huang et al., 2011; Wallace et al., 2014); however, negative opinions create problems (Huang et al., 2011; Balaji et al., 2016) especially because they produce a stronger impact (Christodoulides et al., 2012; Grégoire et al., 2014; Balaji et al., 2016).

The importance of WoM stems from the fact that its actors trust it more than the information conveyed via advertisements or sellers (Edelman, 2010; Jalilvand and Samiei, 2012). Hence, there appear more websites and applications for users to publish opinions about products and services. The power of WoM influences the fact that companies very often use this type of communication in their marketing activity (Wang et al., 2016).

The Internet is a much cheaper and faster way of conveying information in comparison to the traditional means (Lee et al., 2011). We may talk about e-WoM in which websites or smartphone applications act as communication channels between individual users (Chu and Choi, 2011; Cheung and Thadani, 2012; Mikalef et al., 2013; Barreto, 2014). Hennig-Thurau et al. (2004, p. 39) describe e-WoM as "any positive or negative statement made by potential, actual, or former customers about a product or company, which is made available to a multitude of people and institutions via the Internet." E-WoM, especially via social media, operates much quicker and with a much broader range than traditional WoM (Hennig-Thurau et al., 2004; Barreto, 2014). Information from people who live in remote parts of the world are accessible at an instant, and one can share their opinions or observations with others just as quickly (Phelps et al., 2004). Brown et al. (2007) emphasize the importance of e-WoM in consumer decisions because consumers trust this type of channel and information more.

\section{Social Media}

A particularly important event in the growth of e-WoM has been the appearance of social media, which to an even greater extent enable users to communicate quickly and convey content (Mikalef et al., 2013). This relates to the specifications of social media that, according to Kaplan and Haenlein (2010, p. 61), are a set of applications technically and ideologically based on the foundations of Web 2.0, which enable the creation and exchange of content among their users. Scholars sometimes call Web 2.0 "another version of the Internet" that came into being as a result of technological breakthroughs in the second half of the twentieth century. However, Web 2.0 more often refers to the way users utilize the Internet resources. Today, communicating via the Internet usually means using social networking sites (Davies et al., 2016). Therefore, one may speak about social media e-WoM. 
The social media market is extremely large and diversified. A recent report Digital in 2016 report: We are Social shows that over $30 \%$ of the global population actively partakes in social media, $72 \%$ of them are mobile users (Kemp, 2016). The choice of social media depends on the availability and type of activity or service each provides. For example, Instagram offers visual benefits, whereas Twitter allows for microblogging.

Some of the first social media platforms with large numbers of active users around the world were Facebook, YouTube, Qzone, and Twitter. Facebook and Qzone enable conveying different messages as texts, photos, and videos, accessible for the user's friends (Chu and Kim, 2011; Khan and Vong, 2014; Davies et al., 2016). Twitter and YouTube also enable users to express themselves in writing, video, and photography (Kim et al., 2014; Khan and Vong, 2014; Hamid et al., 2015), but anyone may access the content online, rather than just a closed circle of connected users. Markets differ in the availability of particular social media due to national politics and the activity and popularity of local media. In the majority of countries, the data regarding the number of users of particular social media indicate the dominant position of Facebook (Kemp, 2016). However, the most popular platform in Asian countries is Qzone, an equivalent of Facebook with similar functionalities. For this reason, the author decided to analyze Facebook use in Poland, Turkey, and the USA, while Qzone in China.

\section{Gender}

One of the factors that determine the usage of social media is gender. The results of the literature review show how the sexes differ in their use of the Internet. Women are more likely to use the Internet to communicate via e-mail, Internet forums, and social media to build and maintain relationships, while men more often seek information about current events (Ruleman, 2012; Joiner et al., 2012; Special and Li-Barber, 2012; Chan et al., 2015). Moreover, men use the Internet for entertainment and gaming more often than women (Junco, 2010; Muscanell and Guadagno, 2012; Joiner et al., 2012; Chan et al., 2015).

The results of recent research in this field show that women use social media platforms more often than men (Madden and Zickuhr, 2011, Nadkarni and Hofmann, 2012), spend more time in social media, and have fostered more connections there (Moore and McElroy, 2012). The analysis by Lim et al. (2014) shows that women tend to use social media primarily to communicate with friends, while men often to shop or express opinions. This may be so because, compared to men, women tend to avoid the risks of the Internet (Sanchez-Franco et al., 2009). Men more often post online content than women, and it is a skill more highly valued by other men (See-To and Ho, 2014). On 
the other hand, women are more likely to appreciate the ability to appropriately respond to the online and social media information (See-To and Ho, 2014). These results suggest that women in their use of the social media place greater emphasis on security and trust. In turn, men are less sensitive to the dangers of the social media but cherish the opportunity to actively intervene and participate instead (Lim et al., 2014).

To summarize, the previous research on how gender influences Internet and social media use concludes that women use them more for keeping contact with friends and men for entertainment and information. Notwithstanding, sex differences remain underresearched in regard to e-WoM activities via social media, which is why this paper aims to fill this gap.

\section{Method}

\section{Measurement Development and Data Collection}

Methodologically, this paper assumes a deductive approach and aims to answer the research questions arising from the literature study. In the exploratory empirical study, the author employed two research methods: PAPI (Paper and Pen Personal Interview) and CAWI (Computer Assisted Web Interview). The measurement instrument was a standardized questionnaire specifically prepared for the research. The element differentiating the research questionnaire in particular markets was language. In preparation for the different versions of the questionnaire, the author applied back translation procedure to eliminate any mistakes from linguistic, lexical, and context differences (Craig and Douglas, 2006).

The study gathered empirical data in 2016 from China, Poland, the USA, and Turkey. The total number of respondents was 1246, including 295 respondents from China, 296 from Poland, 395 from Turkey, and 260 from the USA. Firstly, the author used CAWI with an online questionnaire as a research instrument filled out by the respondents themselves to collect fast responses. The main advantage of CAWI is shorter time and lower cost of distribution. But the online questionnaire produced only $3.5 \%$ valuable feedback from all collected questionnaires. Secondly, the author used the more expansive and time-consuming PAPI, which nevertheless brought better results. The percentages of PAPI and CAWI in particular groups were: $100 \%$ of PAPI in China, $10 \%$ of CAWI and $90 \%$ of PAPI in Poland, $5.4 \%$ of PAPI and $94.6 \%$ of CAWI in the USA, $100 \%$ of PAPI in Turkey. The differences stem from the difficulties in respondents' recruitment to participate in the research via the Internet. 
Although the author randomly selected CAWI, the number of filled questionnaires was not satisfactory. For PAPI, the author applied non-random sampling method (snowball sampling). Designated research assistants gathered questionnaires from respondents in each market. The applied sampling method influenced the interpretation of the obtained results, which should thus not be fully generalized.

\section{Respondent profile}

All surveyed respondents agreed to participate and stated their willingness to answer how they use social media for e-WoM. The study interviewed people of all ages and distinguished three age groups: 15-20, 21-30, 31>= (Table 1). Most respondents in the Chinese, Polish, and Turkish groups come from the 21-30 range, whereas the majority of USA respondents from the 15-20.

Table 1. The characteristics of respondents by age and gender (\%)

\begin{tabular}{|c|c|c|c|c|}
\hline Features & $\begin{array}{c}\text { China } \\
N=295\end{array}$ & $\begin{array}{l}\text { Poland } \\
\mathrm{N}=296\end{array}$ & $\begin{array}{l}\text { United States } \\
\qquad N=260\end{array}$ & $\begin{array}{l}\text { Turkey } \\
\mathrm{N}=395\end{array}$ \\
\hline \multicolumn{5}{|c|}{ GENDER } \\
\hline $\mathrm{N}$ & $N=293$ & $N=294$ & $N=259$ & $\mathrm{~N}=389$ \\
\hline Women & 68.1 & 70.9 & 56.5 & 48.7 \\
\hline Men & 31.2 & 27.7 & 43.1 & 49.7 \\
\hline No data & 0.7 & 1.3 & 0.4 & 1.5 \\
\hline \multicolumn{5}{|c|}{ AGE } \\
\hline $\mathrm{N}$ & $N=295$ & $N=296$ & $N=260$ & $N=395$ \\
\hline $15-20$ years & 14.2 & 35.5 & 79.6 & 9.6 \\
\hline $21-30$ years & 66.4 & 63.5 & 16.9 & 76.5 \\
\hline $31>=$ & 19 & 0.7 & 3.5 & 13.4 \\
\hline
\end{tabular}

Source: own study.

Noteworthy, no clear predominance of gender appeared in the American and Turkish groups. In contrast, more women answered the Chinese and Polish interviews. 


\section{Operationalization of Variables}

The author devised the following questions on the basis of the literature analysis:

1. Does the frequency of using the most popular social media platform in a given country influence the range of their use of e-WoM among individual users?

2. Which stage of the consumer behavior process (pre-purchase or post-consumption) more depends on the social media for e-WoM activities?

3. Do any differences exist between men and women in this regard?

The measures for the study stemmed from pilot research and the author operationalized variables in three ways. Firstly, in order to identify the frequency of social media use, the study checked the indicators of the structure of the respondents; that is, if they use the social media at least once a day, at least once a week, at least once a month; have account but do not use it or do not use that medium at all. Cronbach Alpha result of 0.774 confirmed that the proposed scale was a reliable tool for measurement (Nunnally, 1978).

Secondly, the study identified the interdependence between the frequency of using the most popular social media (Facebook and Qzone) and the e-WoM in particular stages of consumer behavior with the use of Spearman's rank correlation coefficient. This tool examined the strength of correlation between quantitative characteristics in the case of a small number of observations (Ott and Longnecker, 2015; Hauke and Kossowski, 2011). The author separately calculated every studied group because of their distinctness and the intention to identify differences between them. In order to pinpoint the areas of e-WoM activity via social media, the study asked the respondents to determine the frequency of behaviors by indicating their recurrence: very often, often, from time to time, rarely, very rarely, never; here, again, the Cronbach Alpha result of 0.689 confirmed that the proposed scale was a reliable tool for measuring (Nunnally, 1978). The study divided the behaviors based on the activities before the decision to buy a product (pre-purchase: PRE) and the actions after the use of the bought product (post-consumption: POST). During the pilot research, the respondents predominately indicated the following activities: I look for information about different products ( $\left.\mathrm{PRE}_{1}\right)$; I ask acquaintances for advice concerning the purchase of the product $\left(\mathrm{PRE}_{2}\right)$; I generally recommend to others the products I deem valuable ( $\left.\mathrm{PRE}_{3}\right)$; I express a negative opinion when the product I bought turns out to be of very low quality (POST 1 ); I express a positive opinion and encourage others to buy when the product I bought is valuable ( $\left.\mathrm{POST}_{2}\right)$; I boast about the purchase $\left(\mathrm{POST}_{3}\right)$. These statements were used for the general verification of respondents' behaviors without distinction of particular product categories. 
Thirdly, the study applied Pearson chi2 statistics to determine the significance of differences between gender and the nature of social media use; in general, without distinguishing particular social media. Moreover, the author used the Cramer $V$ ratio to determine the strength of the relationship between sex and indicated behavior. The use of distinguished statistics stems from the characteristics of the measurement scales used in the questionnaire (Hauke and Kossowski, 2011).

\section{Research Results}

The research results show that the social networking service most often used in Poland, the USA, and Turkey is Facebook. In Poland and the USA, the percentage of people who used this medium at least once a day is over $80 \%$ compared to $71.5 \%$ of Turkish respondents (Figure 1). However, the Chinese "equivalent of Facebook," Qzone, was more popular in the Chinese group. In China, only a few people used Facebook on a daily basis, which may effect from the restrictions on the use of this medium in China and the great popularity of local equivalents. Hence, the author decided to ask about Qzone rather than Facebook in the further analysis in the Chinese group (Figure 1).

Figure 1. The frequency of Facebook and Qzone use among the respondents.

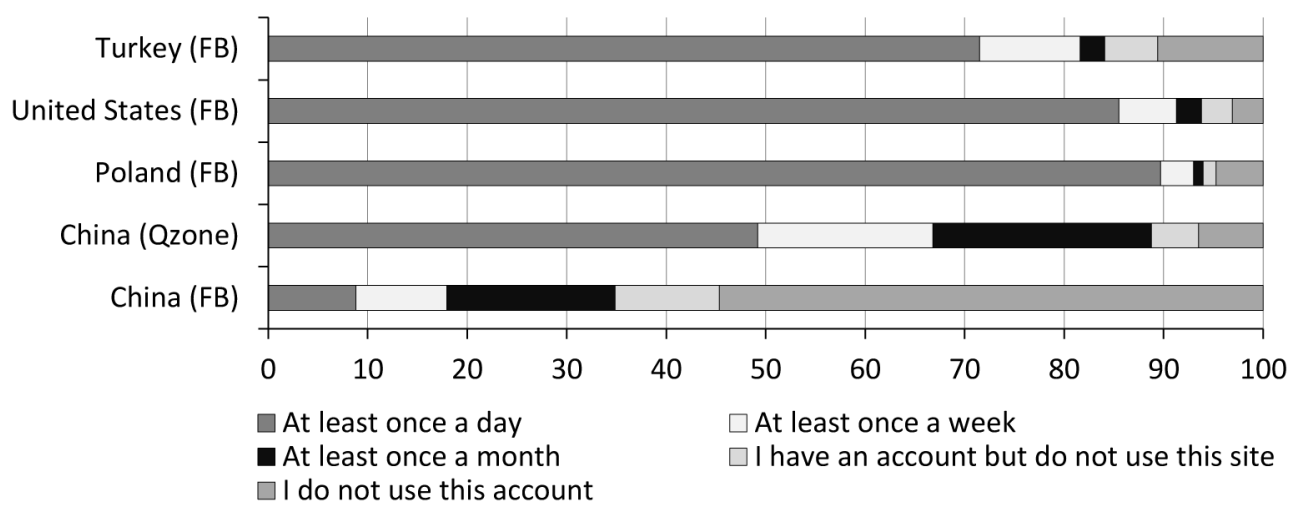

Source: own study.

The results that demonstrate the relations between the frequency of social media use and e-WoM activities appear in Spearman's correlation coefficients in Table 2. In Poland, the USA, and Turkey, the greatest number of relations that indicate the occurrence of correlations is in the Polish group. Here Spearman's coefficients $(p<0.05)$ show the relations between the frequency of using Facebook with $\mathrm{PRE}_{1}, \mathrm{PRE}_{2}$, and $\mathrm{PRE}_{3}$. In other words, the more often the researched Polish respondents used Facebook, 
the more often they used it to seek information about different products $\left(\mathrm{PRE}_{1}\right)$, ask acquaintances for advice in the purchase of a product ( $\left.\mathrm{PRE}_{2}\right)$, and recommend to others the products they deemed valuable $\left(\mathrm{PRE}_{3}\right)$. Only one statistically significant correlation in POST behaviors appeared here (other correlations are not statistically significant). Poles placed negative opinions about low-quality products after consumption - $\mathrm{POST}_{1}$. The study obtained similar results from the Turkish group, in which two statistically significant correlations appeared between the frequency of using Facebook and its application in e-WoM at the PRE-purchase stage ( $\mathrm{PRE}_{1}$ and $\left.\mathrm{PRE}_{2}\right)$. Poles and Turks used social media more often than Americans and Chinese to voice negative opinions when the consumed product was bad ( $\mathrm{POST}_{1}$ ), but not positive opinions when the product was good $\left(\mathrm{POST}_{2}\right)$. In the American group, the study noted no statistically significant correlations. This indicates that the American respondents may not use Facebook for e-WoM activities to the same extent as other researched groups, so they probably use it for other activities distinguished by Whiting and Williams (2013), like social interaction, passing time, entertainment, or relaxation.

Table 2. Spearman's correlation coefficients between the frequency of using Facebook and Qzone and e-WoM activities

\begin{tabular}{|c|c|c|c|c|}
\hline \multirow{2}{*}{ Stage } & $\begin{array}{l}\text { China } \\
\text { Qzone }\end{array}$ & $\begin{array}{l}\text { Poland } \\
\text { FB }\end{array}$ & $\begin{array}{c}\text { United States } \\
\text { FB }\end{array}$ & $\begin{array}{c}\text { Turkey } \\
\text { FB }\end{array}$ \\
\hline & $\mathbf{R}$ & $\mathbf{R}$ & $\mathbf{R}$ & $\mathbf{R}$ \\
\hline $\mathrm{PRE}_{1}$ & $0.143 *$ & 0.127 * & 0.088 & $0.125^{*}$ \\
\hline $\mathrm{PRE}_{2}$ & $0.186^{*}$ & $0.165 *$ & 0.002 & $0.137 *$ \\
\hline $\mathrm{PRE}_{3}$ & $0.129 *$ & $0.117^{*}$ & -0.007 & 0.031 \\
\hline $\mathrm{POST}_{1}$ & $0.135^{*}$ & $0.280 *$ & -0.031 & $0.159 *$ \\
\hline $\mathrm{POST}_{2}$ & 0.013 & 0.054 & -0.045 & 0.076 \\
\hline $\mathrm{POST}_{3}$ & $0.252^{*}$ & -0.011 & -0.025 & -0.045 \\
\hline
\end{tabular}

$\mathbf{R}$ - Spearman Indicator; * Correlation is significant at the $\mathrm{p}<0.05$ level Source: own study.

In the Chinese group, statistically significant correlations $(\mathrm{p}<0.05)$ appeared between the frequency of using Qzone and nearly all e-WoM activities. In other words, the frequency of using Qzone influences the search and transfer of information before the purchase $\left(\mathrm{PRE}_{1}, \mathrm{PRE}_{2}\right.$, and $\left.\mathrm{PRE}_{3}\right)$ and after the consumption of a product in voicing 
negative opinions ( $\mathrm{POST}_{1}$ ) and boasting about the purchase of a new product $\left(\mathrm{POST}_{3}\right)$. The more often the Chinese respondents used Qzone, the more often e-WoM activities abound.

The Pearson chi2 ( $\chi 2)$ statistics indicate that gender influences e-WoM behavior via social media in the Chinese group in the greatest number of activities (Table 3). Chinese women use Qzone more frequently than men to both ask their friends about products $\left(\mathrm{PRE}_{2}\right)$ and share information about them $\left(\mathrm{PRE}_{3}\right)$. Chinese women performed all POST stages more often than men. The V-Cramer indicators show that above relations were at a moderate level. In the Polish group, only two e-WoM activities $\left(\mathrm{PRE}_{1}\right.$ and $\mathrm{POST}_{1}$ ) depended on gender; Polish women also activate more in these elements. In the American group, more women than men recommended various products which they deemed valuable $\left(\mathrm{PRE}_{3}\right)$, negatively appraised should the product turn out to be of very low quality (POST 1 ), and boasted about their purchases $\left(\mathrm{POST}_{3}\right.$ ) via Facebook. In the Turkish group, gender only influenced the e-WoM activities in the POST stage. Turkish women were more eager than men to negatively appraise bad products ( $\left.\mathrm{POST}_{1}\right)$ and boast about new purchases $\left(\mathrm{POST}_{3}\right)$.

Table 3. Correlations between the frequency of using social media for e-WoM activities and gender

\begin{tabular}{|c|c|c|c|c|c|c|c|c|}
\hline \multirow{2}{*}{ Stage } & \multicolumn{2}{|c|}{$\begin{array}{l}\text { China } \\
\text { Qzone }\end{array}$} & \multicolumn{2}{|c|}{$\begin{array}{l}\text { Poland } \\
\text { FB }\end{array}$} & \multicolumn{2}{|c|}{$\begin{array}{c}\text { The United States } \\
\text { FB }\end{array}$} & \multicolumn{2}{|c|}{$\begin{array}{l}\text { Turkey } \\
\text { FB }\end{array}$} \\
\hline & $\chi^{2}$ & $\boldsymbol{V}$ & $\chi^{2}$ & $\boldsymbol{V}$ & $\chi^{2}$ & $\boldsymbol{V}$ & $\chi^{2}$ & $\boldsymbol{V}$ \\
\hline $\mathrm{PRE}_{1}$ & 4.8 & 0.1 & $16.98 *$ & 0.25 & 6.33 & 0.16 & 6.52 & 0.13 \\
\hline $\mathrm{PRE}_{2}$ & $12.05 * *$ & 0.2 & 0.73 & 0.05 & 5.88 & 0.15 & 4.4 & 0.1 \\
\hline $\mathrm{PRE}_{3}$ & $10.3 * *$ & 0.19 & 6.07 & 0.14 & $12.41 * *$ & 0.23 & 7.9 & 0.14 \\
\hline $\mathrm{POST}_{1}$ & $18.65 *$ & 0.3 & $14.04 *$ & 0.32 & $12.73 * *$ & 0.22 & $16.46 *$ & 0.33 \\
\hline $\mathrm{POST}_{2}$ & $11.03 * *$ & 0.2 & 3.97 & 0.12 & 2.08 & 0.09 & 3.8 & 0.1 \\
\hline $\mathrm{POST}_{3}$ & $12.3 * *$ & 0.25 & 6.42 & 0.15 & $14.16^{*}$ & 0.25 & $17.8 *$ & 0.3 \\
\hline
\end{tabular}

$\chi 2$ - Pearson chi2 statistics; $V$ - Cramer`s indicator

* Correlation is significant at $p<0.01 ; * *$ Correlation is significant at $p<0.05$

Source: own study.

Generally, in all the statistically significant correlations, women emerge as more active in e-WoM behaviors via social media than men. Moreover, such situation appeared 
in all groups. Comparing the PRE and POST stages, women more often shared negative opinions if the products they bought were of low quality $\left(\mathrm{POST}_{1}\right)$. Furthermore, they were more critical and eager to share such opinions via social media.

\section{Discussion}

The analyses show relatively few significant differences among the researched countries in relation to the use of social media (Facebook, Qzone) in e-WoM at pre- and post-consumer behavior stages. The American group was the outlier. The study foregrounded the great importance of local social media in the Chinese (Qzone) market. If an enterprise would want to use marketing tools via social media in the Chinese market, it should use Qzone. The results confirm that the frequency social media use influences a whole range of e-WoM activities in Poland, Turkey, and China. There were no statistically significant correlations in the USA, which may stem from the differences in the age of respondent groups. Interestingly, the results also confirmed the findings of the literature analysis that consumers usually use social media at the stage of looking for information and advice about products (pre-purchasing; Chu and Choi, 2011; Baird and Parasnis, 2011; Kucukemiroglu and Kara, 2015; Erkan and Evans, 2016). This study found that only some Poles and Chinese perform the POST stage in the social media. Moreover, after purchase, those respondents more often expressed negative than positive opinions. Earlier studies confirm the problem of the strong influence of negative opinions on the decision of other buyers (Christodoulides et al., 2012; Grégoire et al., 2014; Balaji et al., 2016), but offer no international comparisons of social media use. Thus, answering the second research question, the PRE stage of consumer behavior process depends more on social media than does the POST stage. That is, social media users more actively search and share information about products before purchase than after. The factor of gender as a variable seems to have a particular influence on the POST stage in e-WoM activities. Many more women than men used social media only to express negative opinions after the purchase of a very low-quality product $\left(\mathrm{POST}_{1}\right)$ or boast about a good purchase $\left(\mathrm{POST}_{3}\right)$. Hence, a customer's gender is a significant factor for enterprises which integrate social media into their marketing communication strategy, especially if they offer products or services focused on women. Furthermore, e-WoM behaviors via social media related to gender are similar, regardless of the researched country.

The present study's findings have great application value for enterprises that want to use social media for marketing communication (Hennig-Thurau et al., 2010; Taiminen et al., 2015; Valos et al., 2016). Marketers should be conscious of and monitor the 
method of communication of potential customers to be able to react quickly (O'Reilly and Marx, 2011). The relevant activity of a company may have a particular effect in the markets of the researched groups among which the greatest number of correlations appeared, that is, especially the Chinese market.

\section{Limitations and future research}

Conducting empirical studies with primary methods almost always comes with limitations that only increase in research conducted in multiple countries. Unsurprisingly, the presented research problem and its scope have some limitations as well. Firstly, although respondents reply questionnaires about their behavior in particular situations, their actual behavior could slightly differ from the one declared. The most effective method to minimize this risk is to apply observational research. Some studies gain effectiveness in researching social media use by using qualitative methods. For example, Branthwaite and Patterson`s (2011, p. 439) conclude that "social media monitoring (SMM) is a poor substitute for in-depth qualitative research which has many advantages and benefits." However, in a study across multiple national markets, this method generates considerable costs, which is why researchers often only apply questionnaire methods with closed questions. Another limitation of the presented research is that the non-random sampling and sample size leads to the lack of possibility for extrapolating results to the whole population for each individual country.

Nevertheless, research limitations very often stimulate the further examination of subjects, especially in relation to international activities. More international research on the utility of social media could be expanded and improved via random sampling and larger samples of social media users. In future research, one should ask respondents about their behavior regarding e-WoM via social media after defining specific product categories. Findings of such studies would thus bring more managerial implications for particular producers.

\section{References}

Andreasen, A.R. (1965). Attitudes And Customer Behaviour: A Decision Model. In: L.E. Preston (ed.), New Research In Marketing. Berkeley, Institute of Business and Economic Research, University of California.

Bachleda, C. and Berrada-Fathi, B. (2016). Is negative eWOM more influential than negative pWOM? Journal of Service Theory and Practice, 26(1): 109-132, https://doi.org/10.1108/JSTP-11-2014-0254

Balaji, M.S., Khong, K.W. and Chong, A.Y.L. (2016). Determinants of negative word-of-mouth communication using social networking sites. Information \& Management, 53(4): 528-540. 
Baird, C.H. and Parasnis, G. (2011). From social media to social customer relationship management. Strategy \& Leadership, 39(5): 30-37, https://doi.org/10.1108/10878571111161507

Barreto, A.M. (2013). Do users look at banner ads on Facebook?, Journal of Research in Interactive Marketing, 7(2): 119-139, https://doi.org/10.1108/JRIM-Mar-2012-0013

Blackwell, R.D., Miniard, P.W. and Engel, J.F. (2001). Consumer behavior, South-Western Thompson Learning Publ., UK.

Blocked in China, http://www.blockedinchina.net/?siteurl=facebook.com (4.02.2017).

Branthwaite, A. and Patterson, S. (2011). The power of qualitative research in the era of social media. Qualitative Market Research: An International Journal, 14(4): 430-440, https://doi.org/10.1108/13522751111163245

Brown, J., Broderick, A.J. and Lee, N. (2007). Word of mouth communication within online communities: conceptualizing the online social network. Journal of Interactive Marketing, 21(3): 2-20, https://doi.org/10.1002/dir.20082

Chan, T.Ch.K., Cheung, Ch.M.K., Shi, N. and Lee, M.K.O. (2015). Gender differences in satisfaction with Facebook users. Industrial Management \& Data Systems, 115(1): 182-206, https://doi.org/10.1108/IMDS-08-2014-0234

Cheung, C.M.K. and Thadani, D.R. (2012). The impact of electronic word-of-mouth communication: a literature analysis and integrative model. Decision Support Systems, 54(1): 461-470, https://doi.org/10.1016/j.dss.2012.06.008

Christodoulides, G., Michaelidou, N. and Argyriou, E. (2012). Cross-national differences in e-WOM influence. European Journal of Marketing, 46(11/12): 1689-1707, https://doi.org/10.1108/03090561211260040

Chu, S.C. and Choi, S.M. (2011). Electronic word-of-mouth in social networking sites: a cross-cultural study of the United States and China. Journal of Global Marketing, 24(3): 263-281, https://doi.org/10.1080/08911762.2011.592461

Chu, S.-Ch. and Kim, Y. (2011). Determinants of consumer engagement in electronic word-of-mouth (eWOM) in social networking sites. International Journal of Advertising, 30(1): 47-75, https://doi.org/10.2501/IJA-30-1-047-075

Craig, C.S. and Douglas, S.P. (2006). Beyond national culture: implications of cultural dynamics for consumer research. International Marketing Review, 23(3): 322-342, https://doi.org/10.1108/02651330610670479

Davies, J., Musango, J.K. and Brent, A.C. (2016). A systems approach to understanding the effect of Facebook use on the quality of interpersonal communication Technology in Society, 44: 55-65, https://doi.org/10.1016/j.techsoc.2015.10.003

Deaux, K. and Major, B. (1987). Putting gender into context: an interactive model of gender-related behavior. Psychological Review, 94(3): 369-389, https://doi.org/10.1037/0033-295X.94.3.369

Di Leonardo, M. (1987). The female world of cards and holidays: women, families and the work of kinship. Signs: Journal of Women in Culture in Society, 12(3): 440-453, https://doi.org/10.1086/494338

Edelman, D.C. (2010). Branding in the digital age: you're spending your money in all the wrong places. Harvard Business Review, 88: 62-69.

Engel, J.F., Kollat, D.T. and Blackwell, R.D. (1968). Consumer Behaviour. Chicago: The Dryden Press.

Erkan, I. and Evans, Ch. (2016). The influence of eWOM in social media on consumers' purchase intentions: An extended approach to information adoption. Computers in Human Behavior, 61: 47-55, https://doi.org/10.1016/j.chb.2016.03.003

Galalae, C. and Voicu, A. (2013). Consumer Behaviour Research: Jacquard Weaving in the Social Sciences. Management Dynamics in the Knowledge Economy, 1(2): 277-292. 
Ghezzi, A. and Dramitinos, M. (2016). Towards a Future Internet infrastructure: Analyzing the multidimensional impacts of assured quality Internet interconnection. Telematics and Informatics, 33(2): 613-630, https://doi.org/10.1016/j.tele.2015.10.003

Grégoire, Y., Salle, A. and Tripp, T.M. (2014). Managing social media crises with your customers: the good, the bad, and the ugly. Business Horizons, 58(2): 173-182, https://doi.org/10.1016/j.bushor.2014.11.001

Hamid, S., Waycott, J., Kurnia, S. and Chang, S. (2015). Understanding students' perceptions of the benefits of online social networking use for teaching and learning. The Internet and Higher Education, 26: 1-9, https://doi.org/10.1016/j.iheduc.2015.02.004

Hansen, F. (1972). Consumer Choice Behaviour: A Cognitive Theory. New York: Free Press.

Hauke, J. and Kossowski, T. (2011). Comparison of values of Pearson's and Spearman's correlation coefficient on the same sets of data. Quaestiones Geographicae, 30(2): 87-93, https://doi.org/ 10.2478/v10117-011-0021-1

Hennig-Thurau, T., Gwinner, K., Walsh, G. and Gremler, D. (2004). Electronic word-of-mouth via consumer opinion platforms: what motivates consumers to articulate themselves on the Internet? Journal of Interactive Marketing, 18(1): 38-52, https://doi.org/10.1002/dir.10073

Hennig-Thurau, T., Malthouse, E.C., Friege, C., Gensler, S., Lobschat, L., Rangaswamy, A. and Skiera, B. (2010). The impact of new media on customer relationships. Journal of Service Research, 13(3): 311-330, https://doi.org/ 0.1177/1094670510375460

Ho, Ch.-W. (2014). Consumer behavior on Facebook: Does consumer participation bring positive consumer evaluation of the brand? EuroMed Journal of Business, 9(3): 252-267, https://doi.org/10.1108/EMJB-12-2013-0057

Howard, J.A. and Sheth, J.N. (1969). The Theory of Buyers Behaviour. New York Wiley: Sons.

Hsu, M-H., Tien, S-W., Lin, H-Ch. and Chang, Ch-M. (2015). Understanding the roles of cultural differences and socio-economic status in social media continuance intention. Information Technology \& People, 28(1): 224-241, https://doi.org /10.1108/ITP-01-2014-0007

Huang, M., Cai, F., Tsang, A.S.L. and Zhou, N. (2011). Making your online voice loud: the critical role of WOM information. European Journal of Marketing, 45(7/8): 1277-1297, https://doi.org /10.1108/0309561111137714

Jalilvand, M.R. and Samiei, N. (2012). The effect of electronic word of mouth on brand image and purchase intention: An empirical study in the automobile industry in Iran. Marketing Intelligence \& Planning, 30(4): 460-476, https://doi.org / 10.1108/02634501211231946

Joiner, R., Gavin, J., Brosnan, M., Cromby, J., Gregory, H., Guiller, J. and Moon, A. (2012). Gender, Internet experience, Internet identification, and Internet anxiety: a ten-year followup. Cyberpsychology, Behavior, and Social Networking, 15(7): 370-372, https://doi.org / 10.1089/cyber.2012.0033

Junco, R., Merson, D. and Salter, D.W. (2010). The effect of gender, ethnicity, and income on college students' use of communication technologies. Cyberpsychology, Behavior and Social Networking, 13(6): 619-627, https://doi.org /10.1089/cyber.2009.0357

Kaplan, A.M. and Haenlein, M. (2010). Users of the world, unite! The challenges and opportunities of social media. Business Horizons, 53: 59-68, https://doi.org /10.1016/j.bushor.2009.09.003

Kemp, S. (2016). Digital in 2016 report: We Are Social's, 27 January 2016, http://wearesocial.com/uk/special-reports/digital-in-2016 (10.12.2016).

Kemp, S. (2015). Digital, Social \& Mobile Worldwide in 2015, 21 January 2015, http://wearesocial.net/blog/2015/01/digital-social-mobile-worldwide-2015 (30.11.2016).

Khan, G.F. and Vong, S. (2014). Virality over YouTube: an empirical analysis. Internet Research, 24(5): 629-647, https://doi.org /10.1108/IntR-05-2013-0085 
Kim, K.S., Sin, S.C.J. and Tsai, T.I. (2014). Individual Differences in Social Media Use for Information Seeking. The Journal of Academic Librarianship, 40: 171-178, https://doi.org /10.1016/j.acalib.2014.03.001

Kucukemiroglu, S. and Kara, A. (2015). Online word-of-mouth communication on social networking sites: An empirical study of Facebook users. International Journal of Commerce and Management, 25(1): 2-20, https://doi.org /10.1108/IJCoMA-11-2012-0070

Lee, J., Park, D-H. and Han, I. (2011). The different effects of online consumer reviews on consumers' purchase intentions depending on trust in online shopping malls: An advertising perspective. Internet Research, 21(2): 187-206, https://doi.org /10.1108/10662241111123766

Lim, J-S., Lim, K-S. and Heinrichs, J.H. (2014). Gender and mobile access method differences of Millennials in social media evaluation and usage: an empirical test. The Marketing Management Journal, 24(2): 124-135.

Lin, H., Fan, W. and Chau, P.Y. (2014). Determinants of users' continuance of SNS: a self-regulation perspective. Information $\&$ Management, 51(5): 595-603, https://doi.org. 10.1016/j.im.2014.03.010

Madden, M. and Zickuhr, K. (2011). 65\% of online adults use social networking sites, http://www.pewInternet.org/media/files/reports/2011/pip-sns-update-2011.pdf (4.09.15).

Mikalef, P., Giannakos, M. and Pateli, A. (2013). Shopping and word-of-mouth intentions on social media. Journal of Theoretical and Applied Electronic Commerce Research, 8: 17-34, https://doi.org /10.4067/S0718-18762013000100003.

Moore, K. and McElroy, J.C. (2012). The influence of personality on Facebook usage, wall postings, and regret. Computers in Human Behavior, 28(1): 267-274, https://doi.org /10.1016/j.chb.2011.09.009

Muscanell, N.L. and Guadagno, R.E. (2012). Make new friends or keep the old: gender and personality differences in social networking use. Computers in Human Behavior, 28: 107-112, https://doi.org /10.1016/j.chb.2011.08.016

Nadkarni, A. and Hofmann, S.G. (2012). Why do people use Facebook? Personality and Individual Differences, 52(3): 243-249, https://doi.org /10.1016/j.paid.2011.11.007

Nunnally, J.C. (1978). Psychometric Theory. 2nd Edition. New York: McGraw-Hill.

O'Reilly, K. and Marx, S. (2011). How young, technical consumers assess online WOM credibility. Qualitative Market Research: An International Journal, 14(4): 330-359, https://doi.org /10.1108/13522751111163191

Ott, R.L. and Longnecker, M.T. (2015). An Introduction to Statistical Methods and Data Analysis, 7th Edition, Brooks Cole Ed.

Phelps, J., Lewis, R., Mobilio, L., Perry, D. and Raman, N. (2004). Viral marketing or electronic wordof-mouth advertising: examining consumer responses and motivations to pass along e-mail. Journal of Advertising Research, 44(4): 333-348, https://doi.org /10.1017/S0021849904040371

Ruleman, A.B. (2012). Social media at the university: a demographic comparison. New Library World, 113(7/8): 316-332, https://doi.org /10.1108/03074801211244940

Sanchez-Franco, M.J., Ramos, A.F.V. and Velicia, F.A.M. (2009). The moderating effect of gender on relationship quality and loyalty toward Internet service providers. Information \& Management, 46(3): 196-202, https://doi.org/10.1016/j.im.2009.02.001

Schiffman, L.G., Kanuk, L.L., and Wisenblit, J. (2010). Consumer Behaviour. Tenth Edition. Pearson.

See-To, E.W.K. and Ho, K.K.W. (2014). Value co-creation and purchase intention in social network sites: the role of electronic word-of-mouth and trust - a theoretical analysis. Computers in Human Behaviour, 31(1): 182-189, https://doi.org/ 10.1016/j.chb.2013.10.013

Solomon, M., Bamossy, G., Askegaard, S. and Hogg, M.K. (2010). Consumer Behaviour. A European Perspective. Harlow: Pearson Education. 
Special, W.P. and Li-Barber, K.T. (2012). Self-disclosure and student satisfaction with facebook. Computers in Human Behavior, 28(2): 624-630, https://doi.org /10.1016/j.chb.2011.11.008

Taiminen, H.M. and Karjaluoto, H. (2015). The usage of digital marketing channels in SMEs. Journal of Small Business and Enterprise Development, 22(4): 633-651, https://doi.org / 10.1108/JSBED-05-2013-0073

Trauth, E. (2013). The role of theory in gender and information systems research. Information and Organization, 23(4): 277-293, https://doi.org / 10.1016/j.infoandorg.2013.08.003.

Valos, M.J., Habibi, F.H., Casidy, R., Driesener, C.B. and Maplestone, V.L. (2016). Exploring the integration of social media within integrated marketing communication frameworks. Marketing Intelligence \& Planning, 34(1): 19-40, https://doi.org /10.1108/MIP-09-2014-0169.

Wallace, E., Buil, E. and De Chernatony, L. (2014). Consumer engagement with self-expressive brands: brand love and WOM outcomes. Journal of Product \& Brand Management, 23(1): 33-42, https://doi.org /10.1108/JPBM-06-2013-0326

Wang, T., Yeh, R.K-J., Chen, Ch. and Tsydypov, Z. (2016). What drives electronic word-of-mouth on social networking sites? Perspectives of social capital and self-determination. Telematics and Informatics, 33(4): 1034-1047, https://doi.org /10.1016/j.tele.2016.03.005

Whiting, A. and Williams, D. (2013). Why people use social media: a uses and gratifications approach. Qualitative Market Research: An International Journal, 16(4): 362-369,

https://doi.org /10.1108/QMR-06-2013-0041 